\title{
Characterization of a Lactobacillus brevis strain with potential oral probiotic properties
}

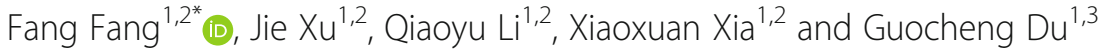

\begin{abstract}
Background: The microflora composition of the oral cavity affects oral health. Some strains of commensal bacteria confer probiotic benefits to the host. Lactobacillus is one of the main probiotic genera that has been used to treat oral infections. The objective of this study was to select lactobacilli with a spectrum of probiotic properties and investigate their potential roles in oral health.

Results: An oral isolate characterized as Lactobacillus brevis BBE-Y52 exhibited antimicrobial activities against Streptococcus mutans, a bacterial species that causes dental caries and tooth decay, and secreted antimicrobial compounds such as hydrogen peroxide and lactic acid. Compared to other bacteria, L. brevis BBE-Y52 was a weak acid producer. Further studies showed that this strain had the capacity to adhere to oral epithelial cells. Coincubation of L. brevis BBE-Y52 with S. mutans ATCC 25175 increased the IL-10-to-IL-12p70 ratio in peripheral blood mononuclear cells, which indicated that L. brevis BBE-Y52 could alleviate inflammation and might confer benefits to host health by modulating the immune system.
\end{abstract}

Conclusions: L. brevis BBE-Y52 exhibited a spectrum of probiotic properties, which may facilitate its applications in oral care products.

Keywords: Lactobacillus brevis, Antimicrobial activity, Hydrogen peroxide, Adhesion, Immunomodulation

\section{Background}

Oral infectious diseases, such as dental caries and periodontal diseases, represent one of the most common infections that severely impact human health [1]. As a result of antibiotics overuse and misuse and the emergence of antibiotic-resistant strains, probiotic therapy has been gradually applied to prevent and alleviate infectious diseases [2-4]. Lactobacillus is one of the main probiotic genera that has been widely studied for its potential roles on oral health. Evidence shows that consumption of milk enriched with Lactobacilllus rhamnosus GG decreases the risk of dental caries in children [5]. Similarly, Lactobacillus reuteri reduces the risk of gingivitis [6]. Therefore, lactobacilli with probiotic

\footnotetext{
* Correspondence: ffang@jiangnan.edu.cn

'Key Laboratory of Industrial Biotechnology, Ministry of Education, School of Biotechnology, Jiangnan University, Wuxi 214122, China

${ }^{2}$ State Key Laboratory of Food Science and Technology, Jiangnan University, Wuxi 214122, China

Full list of author information is available at the end of the article
}

properties may prevent the colonization of oral pathogens through different mechanisms.

Probiotic strains produce antimicrobial components such as hydrogen peroxide and lactic acid, which inhibit the growth of oral pathogens (e.g., Streptococcus mutans). However, excessive acid production by lactobacilli may result in the demineralization of the tooth enamel and contribute to dental caries [7]. Moreover, auto-aggregation of the same strain, co-aggregation with common oral strains, and production of extracellular polysaccharides by probiotics favor the formation of biofilms, which protect bacterial strains against environmental changes and contribute to cell aggregation and colonization $[8,9]$. The adhesion of strains to oral epithelial cells prevents the colonization of pathogens [10]. The modulation of the immune system by probiotics, which affects human health, is assessed by the release of anti-inflammatory cytokine interleukin (IL)-10 and pro-inflammatory cytokine IL-12p70. Strains with high

(C) The Author(s). 2018 Open Access This article is distributed under the terms of the Creative Commons Attribution 4.0 International License (http://creativecommons.org/licenses/by/4.0/), which permits unrestricted use, distribution, and 
IL-10-to-IL-12p70 ratios confer benefits to human health [11].

The aim of this study was to characterize Lactobacillus strains with potential probiotic properties including production of antimicrobial compounds and extracellular polysaccharides and the capability to adhere to oral epithelial cells.

\section{Results}

\section{Isolation of lactobacilli with antimicrobial activity}

We analyzed 32 oral isolates. Among them, one Lactobacillus strain isolated from dental plaque exhibited antimicrobial activities against S. mutans ATCC 25175 (Fig. 1). This strain was identified with 16S rRNA gene and pheS sequence blast and designated L. brevis BBE-Y52. In addition to bacteriocin, hydrogen peroxide is another antimicrobial compound that inhibits bacterial growth. Production of hydrogen peroxide is rare in Lactobacillus due to their weak tolerance to oxygen. However, L. brevis BBE-Y52 produced $0.06-0.15 \mathrm{mM}$ hydrogen peroxide. Lactic acid is another antimicrobial compound that is produced by almost all lactobacilli. Production of lactic acid is necessary for the inhibition of oral pathogens; however, excessive acid production may result in tooth decay. Therefore, we measured the capacity of L. brevis BBE-Y52 to produce acid and compared it to other lactic acid bacteria. We observed that L. brevis BBE-Y52 was a weak acid producer compared with Lactobacillus salivarius T1 and S. mutans ATCC 25175 , based on the difference in average $\mathrm{pH}$ values when cultivated in MRS broth supplemented with various carbon sources (Table 1). Moreover, the final concentration of lactic acid from $L$. brevis BBE-Y52 (1.74 \pm $0.12 \mathrm{~g} / \mathrm{L}$ ) in the broth was lower than that from $L$. salivarius T1 and S. mutans ATCC $25175(2.64 \pm 0.09$ and $2.53 \pm 0.07 \mathrm{~g} / \mathrm{L}$, respectively).

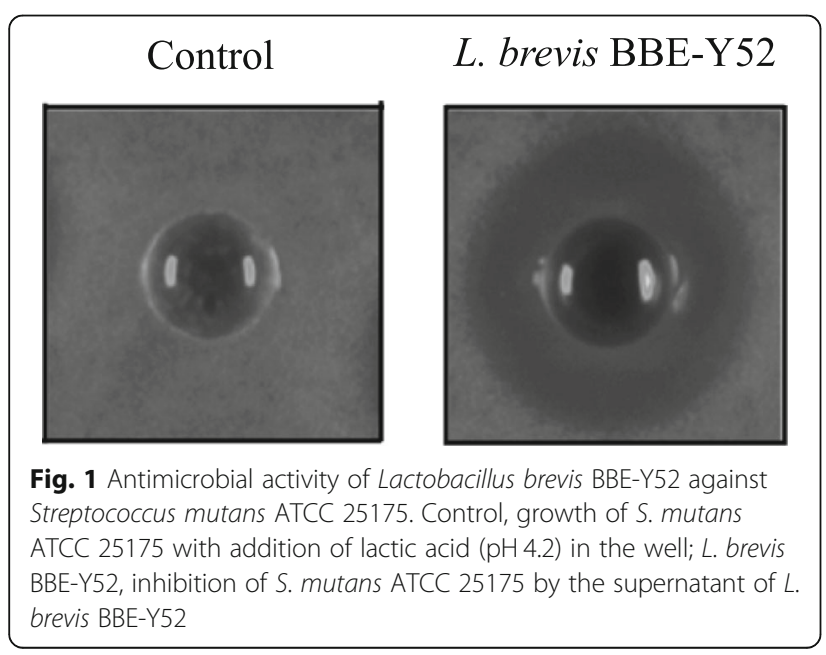

\section{L. brevis BBE-Y52 susceptibility to lysozyme, hydrogen peroxide, and antibiotics}

Microorganisms in the oral cavity may be affected by lysozyme and hydrogen peroxide. We measured the $L$. brevis BBE-Y52 resistance to lysozyme and hydrogen peroxide. L. brevis BBE-Y52 showed tolerance to $1.0 \mathrm{mg} /$ $\mathrm{mL}$ lysozyme, which is much higher than that present in the oral cavity [12]. The L. brevis BBE-Y52 tolerance to hydrogen peroxide was $2.0 \mathrm{mM}$ (Fig. 2). L. brevis BBE-Y52 was resistant to kanamycin and streptomycin and susceptible to ampicillin, tetracycline, and chloramphenicol (Table 2).

\section{Evaluation of the aciduric profile of L. brevis BBE-Y52}

Resistance to acid stress is a very important trait for probiotics and may help them to survival in harsh niches and therefore expand their applications. In this study, resistance of $L$. brevis BBE-Y52 to acid stress was examined, and the aciduric profile of it was compared with that of two Lactobacillus strains (L. casei DSM 20011 and an oral isolate L. paracasei XJ02). As shown in Fig. 3, the survival rate of $L$. brevis BBE-Y52 is higher than that of L. casei DSM 20011 and L. paracasei XJ02 at both $\mathrm{pH} 2.0$ and $\mathrm{pH}$ 3.0. After $3 \mathrm{~h}$ exposure to $\mathrm{pH} 2.0$, no viable cell counts were determined for $L$. casei DSM 20011, while the survival rate for L. brevis BBE-Y52 and L. paracasei XJ02 were $0.027 \%$ (3.6 log cycles reduction in viable cell numbers) and $0.014 \%$ (3.9 log cycles reduction in viable cell numbers), respectively.

\section{Biofilm formation and adhesion of L. brevis BBE-Y52 to KB cells}

Biofilms confer protection to microorganisms against environmental changes. Both EPS production and aggregation of bacteria contribute to biofilm formation. $L$. brevis BBE-Y52 formed viscous colonies and produced $106.6 \mathrm{mg} / \mathrm{L}$ EPS.

The ability of L. brevis BBE-Y52 to auto-aggregate and aggregate with other bacteria was investigated and compared with that of oral pathogens including Streptococcus mutans, Porphyromonas gingivalis and Fusobacterium nucleatum. All tested strains exhibited a capacity to auto-aggregate after $3 \mathrm{~h}$ incubation (Fig. 4). The L. brevis BBE-Y52 auto-aggregation capacity was higher than that of all tested strains except S. mutans ATCC 25175. L. brevis BBE-Y52 exhibited co-aggregation with all tested strains, reduced $S$. mutans ATCC 25175 aggregation significantly, and slightly reduced $P$. gingivalis GIM 1.851 and F. nucleatum CGMCC 1.2528 aggregation. Formation of mature biofilm by L. brevis BBE-Y52 and $S$. mutans ATCC 25175 was observed following $24 \mathrm{~h}$ incubation. $S$. mutans ATCC 25175 exhibited a stronger capacity for biofilm formation than $L$. brevis BBE-Y52. Co-culture of $L$. 
Table 1 Acid production by Lactobacillus brevis BBE-Y52, Lactobacillus salivarius, and Streptococcus mutans

\begin{tabular}{|c|c|c|c|c|c|c|}
\hline \multirow[t]{2}{*}{ Strains } & \multicolumn{4}{|l|}{$\mathrm{pH}^{\mathrm{a}}$} & \multirow{2}{*}{$\begin{array}{l}\text { Average } \\
\mathrm{pH}^{\mathrm{b}}\end{array}$} & \multirow{2}{*}{$\begin{array}{l}\text { Lactic acid } \\
(\mathrm{g} / \mathrm{L})\end{array}$} \\
\hline & Glucose & Sucrose & Lactose & Fructose & & \\
\hline L. brevis BBE-Y52 & $3.86 \pm 0.01$ & $4.02 \pm 0.03$ & $4.07 \pm 0.02^{*}$ & $3.77 \pm 0.03$ & $3.93^{*}$ & $1.74 \pm 0.12^{* *}$ \\
\hline L. salivarius T1 & $3.81 \pm 0.03$ & $3.90 \pm 0.04$ & $3.98 \pm 0.02$ & $3.80 \pm 0.02$ & 3.87 & $2.64 \pm 0.09$ \\
\hline S. mutans ATCC 25175 & $3.90 \pm 0.02^{*}$ & $3.87 \pm 0.03^{*}$ & $3.95 \pm 0.01$ & $3.74 \pm 0.03$ & 3.86 & $2.53 \pm 0.07$ \\
\hline
\end{tabular}

${ }^{\mathrm{a}}, \mathrm{pH}$ values of strain cultures grown in medium containing single carbon source; ${ }^{\mathrm{b}}$, average pH values; ${ }^{\mathrm{c}}$, production of lactic acid by corresponding strains cultivated in MRS broth

* and ${ }^{* *}$ represent significant $(P<0.05)$ and extremely significant $(P<0.01)$ differences based on Student's t-test

brevis BBE-Y52 with S. mutans ATCC 25175 resulted in a reduction of biofilm formation by the pathogen (Fig. 5).

Colonization in the oral cavity is an important property for a probiotic strain. We evaluated the adhesion of probiotic strains to the human oral epithelial cell line $\mathrm{KB}$ using the quantitative (viable adherent cell counting) method. L. brevis BBE-Y52 exhibited a capacity to adhere to $\mathrm{KB}$ cells. The ratio of viable adherent $L$. brevis BBE-Y52 cells to KB cells was $15 \pm 2$ : 1 .

\section{L. brevis BBE-Y52 effects on cytokine production by human PBMCs}

Immunomodulation is an important mechanism that affects human health. Strains with immunomodulatory properties are desirable. Therefore, L. brevis BBE-Y52 immunomodulatory properties were evaluated by measuring the release of cytokines, including pro-inflammatory IL-12p70 and anti-inflammatory IL-10. In the model of cellular immunity analysis, S. mutans ATCC 25175 caused inflammation in PBMCs, indicated by the decreased IL-10-to-IL-12p70 ratio. Co-culturing of PBMCs with $L$. brevis BBE-Y52 increased IL-10 levels and decreased the
IL-10-to-IL-12p70 ratio (Table 3). In S. mutans ATCC 25175-inflamed PBMCs, L. brevis BBE-Y52 significantly increased the IL-10-to-IL-12p70 ratio from 4.1 to 3.8 , suggesting that $L$. brevis BBE-Y52 could alleviated inflammation in PBMCs (Table 3).

\section{Discussion}

Lactobacilli with probiotic properties have been used in clinical trials due to their role in oral health [13-16]. Lactobacillus crispatus, Lactobacillus fermentum, and Lactobacillus gasseri (oral isolates) and L. rhamnosus LGG (a non-oral isolate) have oral probiotic properties including reduction of oral pathogens counts and adherence to oral epithelial cells $[17,18]$. In this study, L. brevis BBE-Y52, a strain isolated from the dental plaque of a healthy donor, exhibited oral probiotic properties such as inhibition of the oral pathogen species $S$. mutans, reduction of aggregation of $S$. mutans, $P$. gingivalis and $F$. nucleatum, production of hydrogen peroxide, resistant to acidic condition, adherence to $\mathrm{KB}$ cells, and alleviation of inflammation. This is the first time that a Lactobacillus strain is shown to have so many composite oral

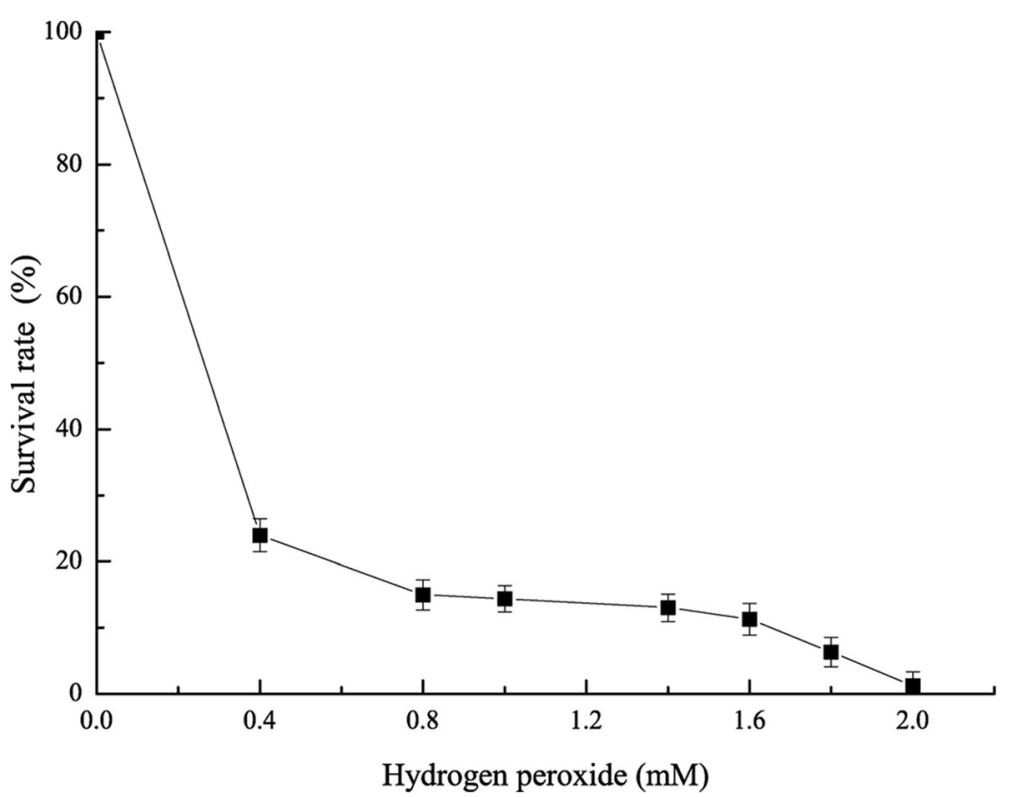

Fig. 2 Tolerance of Lactobacillus brevis BBE-Y52 to hydrogen peroxide 
Table 2 The tolerance of $L$. brevis BBE-Y52 to antibiotics

\begin{tabular}{llllllll}
\hline Antibiotics $(\mu \mathrm{g} / \mathrm{L})$ & 1 & 2 & 4 & 8 & 16 & 32 & 64 \\
\hline ampicillin & - & - & - & - & - & - & - \\
chloramphenicol & + & + & - & - & - & - & - \\
tetracycline & + & + & + & - & - & - & - \\
kanamycin & + & + & + & + & + & + & + \\
streptomycin & + & + & + & + & + & + & + \\
\hline
\end{tabular}

+ , tolerant; - , susceptible

probiotic properties, which indicating the potential applications (inhibition or exclusion of oral pathogens, persistence in oral cavity, anti-inflammation) of $L$. brevis BBE-Y52 in oral care products.

It has been shown that a few Lactobacillus strains exhibited capability of inhibition oral pathogens. L. rhamnosus LGG, a human probiotic, reduces the counts of oral pathogens Streptococcus sanguinis and Candida albicans and reduces the biofilm-forming ability of Fusobacterium nucleatum, an oral bacterium associated with periodontal disease [18]. Mishra et al. demonstrated that a probiotic rinse (containing Streptococcus) was as effective as a chlorhexidine digluconate rinse in reducing $C$. albicans counts [19]. Lactobacillus strains isolated from the oral cavity showed antibacterial activity against the periodontal pathogen Porphyromonas gingivalis, but they did not inhibit the growth of Prevotella intermedia or $S$. mutans when the acid effect was removed [17]. Lactic acid produced by lactic acid bacteria inhibits the growth of Gram-negative bacteria including the oral pathogen $P$. gingivalis [20]. In this study, the antimicrobial activity of L. brevis BBE-Y52 against S. mutans was confirmed after removing the lactic acid effect (Fig. 1). This probiotic might inhibit the growth of other oral pathogens. However, lactic acid may potentially weaken the tooth enamel [7]. Therefore, a weak lactic acid producer is more suitable for oral care products. Compared to other Lactobacillus strains tested in this study and those previously reported (Lactobacillus acidophilus CRL 1259 and Lactobacillus strain L1 and L2 produce 8.57-9.28 and $8.85 \mathrm{~g} / \mathrm{L}$ lactic acid, respectively) [21, 22], L. brevis BBE-Y52 is a weak lactic acid producer. Moreover, $L$. brevis BBE-Y52 survives better at $\mathrm{pH} 2.0$ and $\mathrm{pH} 3.0$ than other two tested Lactobacillus strains (Fig. 3). After $3 \mathrm{~h}$ treatment at $\mathrm{pH} 2.0$, the viable cell number of $L$. brevis BBE-Y52 is 3.6 log cycles reduction, this is much better than that of $90 \%$ probiotic Lactobacillus strains (1.5-9.0 log cycles reduction) [23]. Hydrogen peroxide is another antimicrobial substance that can be produced by streptococci and some commensal lactobacilli [24]. L. brevis BBE- Y52 produced up to $0.15 \mathrm{mM}$ hydrogen peroxide when grown in MRS broth in microaerobic conditions. This is lower than that of the intestine isolate Lactobacillus johnsonii NCC 533, which produces $1 \mathrm{mM}$ hydrogen peroxide when cultivated in LAPTg medium under aerobic conditions [24]. L. brevis BBE- Y52 is competitive, because L. johnsonii NCC 533 hardly produces any hydrogen peroxide in anaerobic conditions [24].

In this study, the co-aggregation with L. brevis BBE-Y52 decreased S. mutans P. gingivalis and F. nucleatum aggregation (Fig. 4), which may in part reduce the risk of dental caries and periodontal disease. The capacity to co-aggregate with oral microbes and form biofilms may contribute to L. brevis BBE-Y52 colonization

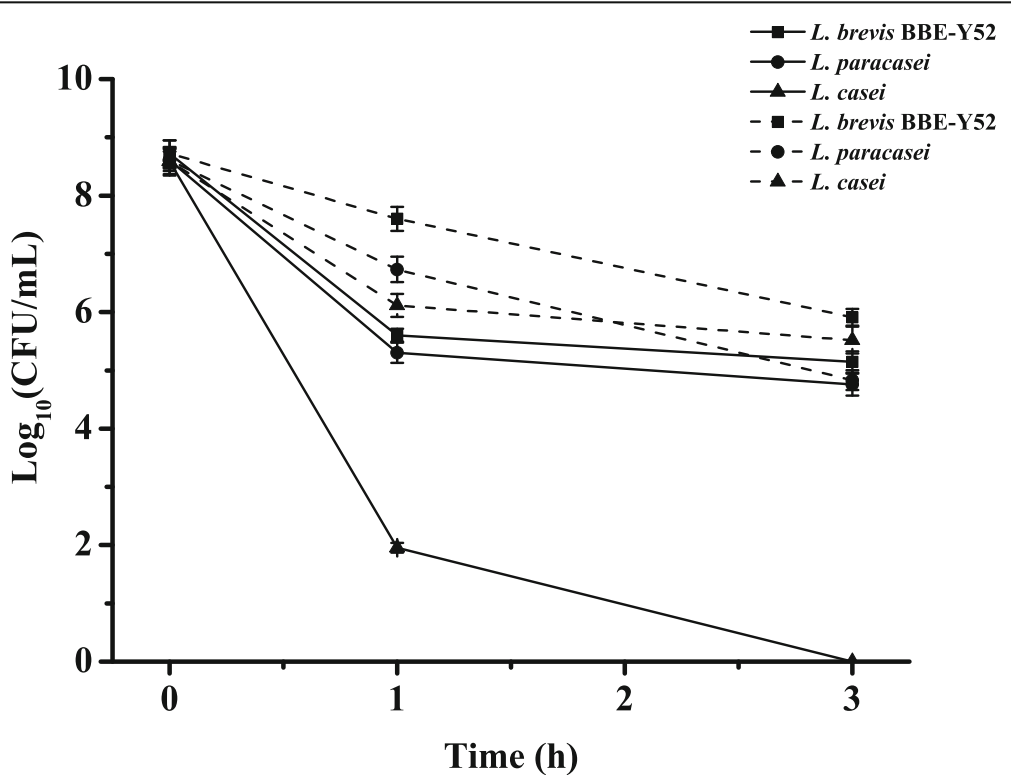

Fig. 3 Aciduric profile of Lactobacillus brevis BBE-Y52. Survival of Lactobacillus strains challenged with acidic conditions at pH 2.0 (lines) and pH 3.0 (dot lines) 


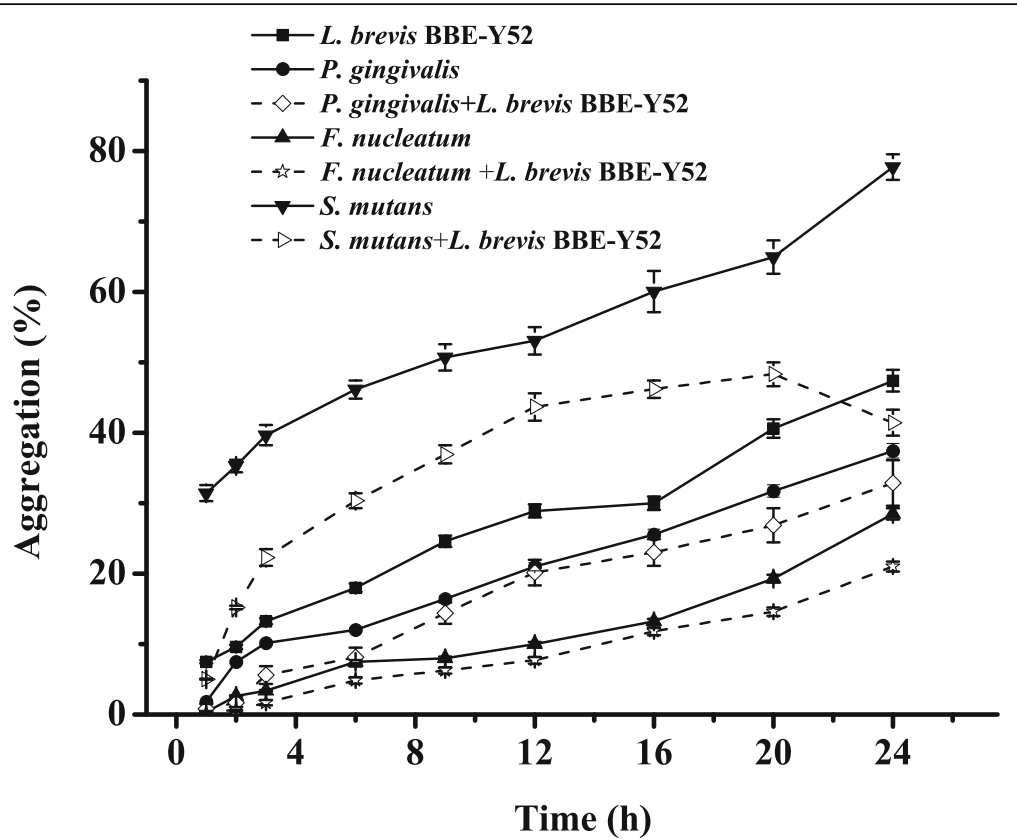

Fig. 4 Auto-aggregation of Lactobacillus brevis BBE-Y52 and coaggregation of BBE-Y52 with oral pathogens. Auto-aggregation (lines) of individual strain and coaggregation (dot lines) of BBE-Y52 with oral pathogens. Solid symbols: square, L. brevis BBE-Y52; circle, Porphyromonas gingivalis GIM1.851; upper triangle, Fusobacterium nucleatum CGMCC 1.2528; lower triangle, Streptococcus mutans ATCC 25175; Open symbols: right triangle, L. brevis BBE-Y52 + S. mutans ATCC 25175; diamond, L. brevis BBE-Y52 + P. gingivalis GIM1.851; star, L. brevis BBE-Y52 + F. nucleatum CGMCC 1.2528

in the oral cavity. In addition, the adherence ratio of $L$. brevis BBE-Y52 to KB cells was $(15 \pm 2)$ : 1 , which demonstrated that $L$. brevis BBE-Y52 has the capacity to adhere to $\mathrm{KB}$ cells, based on classification criteria [25]. Saeed and Heczko demonstrated that lactobacilli with high auto-aggregation are highly adherent to the KB cell line [26], consistent with our findings. Lactobacillus strains of oral origin adhered to oral epithelial cells with an adherence of 60 bacterial cells $/ \mathrm{mm}^{2}$ for $\mathrm{HO}$ and/or HSC cells [17]. According to MIC analysis, L. brevis

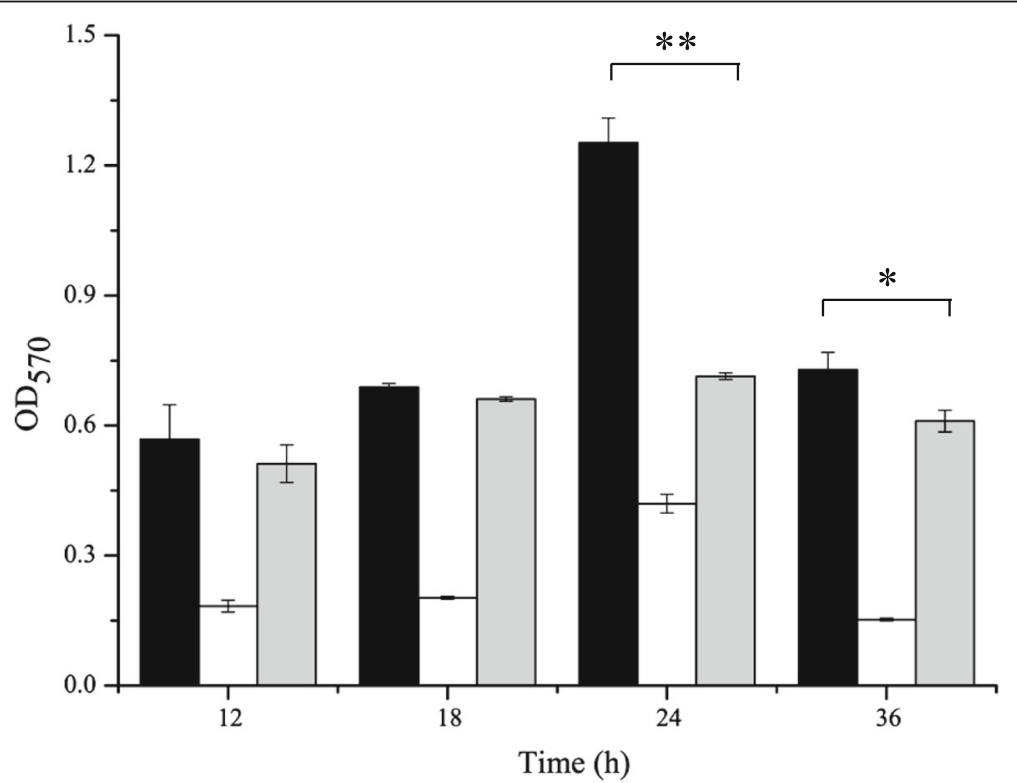

Fig. 5 Biofilm formation by Lactobacillus brevis BBE-Y52 and S. mutans ATCC 25175. Black bars, white bars and grey bars represent the biofilm formed by individual Streptococcus mutans ATCC 25175 , L. brevis BBE-Y52, and both strains, respectively. ${ }^{*}$ and ${ }^{* *}$ represent significant $(P<0.05)$ and extremely significant $(P<0.01)$ differences based on Student's t-test 
Table 3 PBMC cytokine levels in response to co-culturing with L. brevis BBE-Y52 or S. mutans

\begin{tabular}{|c|c|c|c|c|c|}
\hline \multirow[t]{2}{*}{ Cytokine } & \multicolumn{3}{|l|}{ aPBMCs } & \multicolumn{2}{|c|}{ bPBMCs + S. mutans } \\
\hline & Control & BBE-Y52 & S. mutans & Control & BBE-Y52 \\
\hline $\mathrm{IL}-10\left(\mathrm{pg} \mathrm{mL} \mathrm{L}^{-1}\right)$ & $164 \pm 2$ & $186 \pm 2$ & $177 \pm 4$ & $248 \pm 2$ & $243 \pm 3$ \\
\hline IL-12p70 (pg mL $\left.{ }^{-1}\right)$ & $28 \pm 2$ & $31 \pm 1$ & $33 \pm 1$ & $65 \pm 2$ & $59 \pm 2$ \\
\hline IL-10/IL-12p70 & $5.8 \pm 0.2$ & $6.1 \pm 0.1^{*}$ & $5.4 \pm 0.1^{*}$ & $3.8 \pm 0.1$ & $4.1 \pm 0.1^{*}$ \\
\hline
\end{tabular}

a, PBMCs incubated either alone (control) or with BBE-Y52/S. mutans for $12 \mathrm{~h}$; ${ }^{\mathrm{b}}$, S. mutans treated PBMCs was incubated either alone (control) or with BBE-Y52 for $24 \mathrm{~h} ;{ }^{*}$ IL-10-to-IL-12p70 ratio was significant $(P<0.05)$ based on Student's t-test

BBE- Y52 is resistant to kanamycin and streptomycin, but susceptible to ampicillin, chloramphenicol and tetracycline. In contrast, Lactobacillus plantarum and Lactobacillus oris strains are resistant to tetracycline [27, 28]. L. brevis BBE-Y52 tolerates $1 \mathrm{mg} / \mathrm{mL}$ lysozyme, some oral lactobacilli tolerate up to $10 \mathrm{mg} / \mathrm{mL}$ lysozyme [28], while $L$. plantarum strains tolerate up to $0.1 \mathrm{mg} / \mathrm{mL}$ lysozyme [29]. Immunomodulation by probiotics is an important aspect that confers benefits on human health. Immunomodulation can be evaluated by the release of cytokines as key regulators. Following co-incubation of inflamed PBMCs (by S. mutans) with L. brevis BBE-Y52, inflammation subsided based on the increase in IL-10-to-IL-12p70 ratio (Table 2).

\section{Methods}

\section{Strains and growth conditions}

Lactobacillus strains were grown in de man, Rogosa, Sharpe (MRS, Oxoid, Hampshire, UK) medium and incubated at $37^{\circ} \mathrm{C}$ under microaerophilic conditions (5\% $\mathrm{CO}_{2}$ ) for 24-48 h. S. mutans ATCC 25175 was grown in brain heart infusion medium (BHI, Oxoid, Hampshire, UK) at $37^{\circ} \mathrm{C}$ under microaerophilic conditions. Porphyromonas gingivalis GIM1.851 and Fusobacterium nucleatum CGMCC 1.2528 were grown at $37^{\circ} \mathrm{C}$ anaerobically in TSB medium and PYG medium, respectively.

\section{Lactobacilli isolation and identification from human saliva and dental plaques}

Human saliva and dental plaques samples of 10 healthy donors (five female and five male; mean age $24 \pm 3$ years) were obtained from Wuxi No. 2 People's Hospital (Wuxi, Jiangsu Province, China) according to the method reported by Krajden [30]. Lactobacillus strains were isolated by plating the serial diluted samples on MRS agar and cultivated at $37^{\circ} \mathrm{C}$ under microaerophilic conditions. Genomic DNA of Lactobacillus strains were extracted using EZNA genomic DNA isolation kits (Omega Bio-Tek, Doraville, USA). Strains were identified by analysis of $16 \mathrm{~S}$ rDNA (amplified by primers 16SF 5'-TACGGYTACC TTGTTACGACTT-3' and 16SR 5'-AGAGTTTGATCM TGGCTCAG-3') and pheS (amplified by primers pheSF 5'-TTCCCATTTACGGAGCCTTCTG-3' and pheSR 5'GCACCATACCGGCACCTAACAC-3') sequences and blasted against the NCBI database.

\section{Antimicrobial activity assay}

Antimicrobial activities of isolates against $S$. mutans ATCC 25175 were evaluated by the agar well-diffusion method [31]. Briefly, $10 \mathrm{~mL}$ of base agar $(1.5 \%, w / v)$ was plated on a Petri dish and allowed to cool before placing on sterile Oxford Cups. S. mutans ATCC 25175 (final concentration in agar: $10^{6} \mathrm{CFU} / \mathrm{mL}$ ) was mixed with 10 $\mathrm{mL}$ of semi-solid BHI agar $(0.8 \%$, w/v) and overlaid on the base agar. Oxford Cups were removed when the upper layer set. Finally, $100 \mu \mathrm{L}$ of supernatant of bacterial culture or heat-inactivated supernatant (control) was added to wells and incubated at $37^{\circ} \mathrm{C}\left(5 \% \mathrm{CO}_{2}\right)$ for $24 \mathrm{~h}$. The inhibition zones represent the growth inhibition of S. mutans ATCC 25175 by corresponding strains.

\section{Analysis of acid production}

Lactobacillus strains and S. mutans were inoculated in MRS broth (devoid of carbon source) supplemented with single carbon source (equal moles of glucose, sucrose, lactose, and fructose) and grown at $37^{\circ} \mathrm{C}$ and $5 \%$ $\mathrm{CO}_{2}$ for $24 \mathrm{~h}$. Following a 24-h incubation, the $\mathrm{pH}$ value of the broth was measured. Production of lactic acid by these strains grown in MRS at $37^{\circ} \mathrm{C}\left(5 \% \mathrm{CO}_{2}\right)$ for $24 \mathrm{~h}$ was determined with high performance liquid chromatography using a modified method [32]. Strains were removed by centrifugation at 10,000 rpm for $10 \mathrm{~min}$. Corresponding supernatants were passed through a $0.22-\mu \mathrm{m}$ membrane filter, and $20 \mu \mathrm{L}$ of the filtrate or its dilution was injected onto HPLC for lactic acid quantification. Separation was performed using an HPLC organic acid analysis column $(300 \mathrm{~mm} \times 7.8 \mathrm{~mm}$, BIO-RAD, Hercules, CA, USA) at $40{ }^{\circ} \mathrm{C}$, using $0.05 \mathrm{mM}$ sulfuric acid as the mobile phase (flow rate $0.6 \mathrm{~mL} / \mathrm{min}, 30 \mathrm{~min}$ ). Lactic acid was detected at $210 \mathrm{~nm}$.

\section{Detection of acid resistance of Lactobacillus}

L. brevis BBE-Y52, L. casei DSM 20011 and L. paracasei XJ02 (a strain isolated from oral cavity, this study) were grown in MRS broth at $37^{\circ} \mathrm{C}$. Cells of these strains collected during the exponential growth phase were harvested by centrifugation $(8000 \mathrm{rpm}, 5 \mathrm{~min})$, and then washed three times with phosphate buffer saline (PBS, $\mathrm{pH}$ 7.2) before suspended in PBS or PBS adjusted to $\mathrm{pH}$ 2.0 and 3.0 using $5 \mathrm{M} \mathrm{HCl}$, and incubated at $37^{\circ} \mathrm{C}$. Samples of each solution were taken at different time 
intervals, diluted and plated on MRS agar. Cell numbers were counted and used for calculating the survival rate.

\section{Detection of extracellular polysaccharides (EPS) and hydrogen peroxide}

Bacterial strains were grown on MRS agar containing $10 \%(w / v)$ sucrose, and the plates were incubated at $30^{\circ}$ $\mathrm{C}$ for $48 \mathrm{~h}$. Strains that appeared as viscous colonies were considered to be EPS producers [33]. For quantitative analysis of EPS, strains were grown at $30{ }^{\circ} \mathrm{C}$ for $48 \mathrm{~h}$ in MRS broth containing $10 \%(\mathrm{w} / \mathrm{v})$ sucrose. Proteins in cultures were precipitated with trichloroacetic acid (Sigma-Aldrich, St. Louis, MO, USA) and stirred for 30 min on ice. Following centrifugation at $15,000 \mathrm{~g}$ for 30 min at $4{ }^{\circ} \mathrm{C}$, cold ethanol (three times the volume) was added to the supernatant and stored overnight at $4{ }^{\circ} \mathrm{C}$ to precipitate EPS. The sediment was collected by centrifugation at $15,000 \mathrm{~g}$ for $30 \mathrm{~min}$ at $4{ }^{\circ} \mathrm{C}$ and dissolved in distilled water. EPS was determined by phenol-sulfuric acid method using D-glucose as a standard [34].

To measure hydrogen peroxide production, bacterial strains were grown in MRS broth and incubated at $37{ }^{\circ} \mathrm{C} \quad\left(\begin{array}{lll}5 \% & \mathrm{CO}_{2}\end{array}\right)$ for $24 \mathrm{~h}$. Hydrogen peroxide in cell-free supernatant of corresponding bacterial cultures was measured using semi-quantitative test strips (Merck, Poole, UK), which detect hydrogen peroxide at 0 to $25 \mathrm{mg} / \mathrm{L}$.

\section{Lysozyme, hydrogen peroxide, and antibiotic susceptibility}

The susceptibility of lactobacilli $\left(10^{7} \mathrm{CFU} / \mathrm{mL}\right)$ to lysozyme (Thermo Fisher, Waltham, MA, USA) was examined by an agar well-diffusion method [28]. Susceptibility to hydrogen peroxide (Sigma-Aldrich) was evaluated by the survival of the corresponding strain when exposed to hydrogen peroxide [35]. The Lactobacillus strain was cultivated in MRS at $37^{\circ} \mathrm{C}\left(5 \% \mathrm{CO}_{2}\right)$ for $24 \mathrm{~h}$. Cells were harvested by centrifugation ( $8000 \mathrm{rpm}, 15 \mathrm{~min}$ ) and rinsed twice with phosphate-buffered saline (PBS, $\mathrm{pH}$ 7.0) before re-suspending $\left(10^{8} \mathrm{CFU} / \mathrm{mL}\right)$ in PBS containing 0-2 $\mathrm{mM}$ hydrogen peroxide at $37^{\circ} \mathrm{C}\left(5 \% \mathrm{CO}_{2}\right)$ for $1 \mathrm{~h}$. Corresponding cultures were plated in MRS agar, and viable cells were counted and compared with the control (0 mM hydrogen peroxide). Survival rate was calculated to evaluate the resistance to hydrogen peroxide. Antibiotic susceptibility of lactobacilli was determined by the disk diffusion method [36]. Strains were classified as resistant or susceptible by comparing the minimum inhibitory concentrations of antibiotics (Sigma-Aldrich) with European Food Safety Authority standards [37].

\section{Aggregation assays}

Bacterial aggregation of single strain (auto-aggregation) and two strains were examined [38, 39]. Cells of $S$. mutans ATCC 25175, P. gingivalis GIM1.851 and F. nucleatum CGMCC 1.2528 collected during the exponential growth phase were harvested, cells were washed twice with $\mathrm{PBS}$, and suspended in $\mathrm{PBS}$ to an $\mathrm{OD}_{600}$ value of $0.5\left(\mathrm{~A}_{0}\right)$. Absorbance at $600 \mathrm{~nm}$ of the upper suspension $\left(A_{t}\right)$ was measured after $1-3 \mathrm{~h}$ incubation. Coaggregations of oral lactobacilli with the foregoing strains were determined by combining equal volumes $(500 \mu \mathrm{L})$ of the adjusted suspensions of isolates $\left(\mathrm{A}_{\text {probio }}\right)$ and oral pathogens $\left(\mathrm{A}_{\text {pat }}\right)$. Coaggregation was calculated using the formula described by Collado [38].

\section{Auto-aggregation $(\%)=\left(\mathrm{A}_{0}-\mathrm{A}_{\mathrm{t}}\right) / \mathrm{A}_{0} \times 100$.}

Coaggregation $(\%)=\left[\left(\mathrm{A}_{\text {pat }}+\mathrm{A}_{\text {probio }}\right) / 2-\left(\mathrm{A}_{\text {mix }}\right) /\left(\mathrm{A}_{\text {pat }}+\right.\right.$ $\left.\left.\mathrm{A}_{\text {probio }}\right) / 2\right] \times 100$.

where $A_{\text {mix }}$ represents absorbance at $600 \mathrm{~nm}$ of culture of two strains.

\section{Biofilm formation assays}

The formation of biofilm by oral isolates and S. mutans ATCC 25175 was assessed using the microtiter plate method [40]. Lactobacillus strains and S. mutans were cultivated in MRS or BHI at $37{ }^{\circ} \mathrm{C}\left(5 \% \mathrm{CO}_{2}\right)$ for $24 \mathrm{~h}$. Subsequently, $125 \mu \mathrm{L}$ of cell suspensions $\left(\mathrm{OD}_{600}=1.0\right)$ of individual strains were added to wells of a 24-well plate containing $875 \mu \mathrm{L}$ BHI broth $(750 \mu \mathrm{L}$ BHI broth for two strains), and incubated at $37^{\circ} \mathrm{C}\left(5 \% \mathrm{CO}_{2}\right)$ for $12-36 \mathrm{~h}$. Cell suspensions were removed by careful pipetting. Wells were rinsed three times with PBS and air-dried for $30 \mathrm{~min}$. Wells were stained with crystal violet $(1 \%, w / v)$ for $20 \mathrm{~min}$, rinsed with PBS, and air-dried for $30 \mathrm{~min}$. Ethanol (1 mL, 95\%) was added, and absorbance at 570 nm was measured.

\section{Adhesion assays}

The oral epithelial carcinoma cell line (KB) was used to assess the adhesion of oral lactobacilli $[41,42]$. KB cells (provided by Prof. Jian Jin, and purchased from ATCC, Manassas, VA, USA) were grown in minimum essential medium (MEM; Invitrogen, Carlsbad, CA, USA) supplemented with $10 \%(v / \mathrm{v})$ fetal bovine serum (Invitrogen) at $37^{\circ} \mathrm{C}\left(5 \% \mathrm{CO}_{2}\right)$. A concentration of $3.0 \times 10^{5} \mathrm{~KB}$ cells was seeded in 35-mm-diameter dishes (Corning, New York, NY, USA) and incubated until the formation of a complete monolayer. The KB cells monloayer was washed twice with PBS, and an aliquot of $2 \mathrm{~mL}$ minimum essential medium (MEM, Invitrogen) was added to the plates and incubated at $37^{\circ} \mathrm{C}\left(5 \% \mathrm{CO}_{2}\right)$ for $30 \mathrm{~min}$. The bacterial cultures were washed and suspended in MEM $\left(10^{8} \mathrm{CFU} / \mathrm{mL}\right)$. Bacterial suspension $(120 \mu \mathrm{L})$ was seeded onto the KB cells monolayer and incubated for 1 $\mathrm{h}$ at $37^{\circ} \mathrm{C}\left(5 \% \mathrm{CO}_{2}\right)$. The $\mathrm{KB}$ cells monolayer were subsequently washed to remove unattached bacteria. Methanol (3 mL) was added to fix the cells $(10 \mathrm{~min})$ and removed prior to staining with $3 \mathrm{~mL}$ Giemsa stain for 
$30 \mathrm{~min}$. For detecting the adhesion of lactobacilli to $\mathrm{KB}$ cells, the dishes were rinsed, dried at $37^{\circ} \mathrm{C}$ for $16 \mathrm{~h}$, and examined by microscopy [42]. To quantify the adhesion capability of bacteria to $\mathrm{KB}$ cells, the monolayers were lysed with distilled water. Corresponding solutions were plated on MRS, and viable adherent bacteria were counted. Adhesive capacity was determined according to the number of strains that adhered to one KB cell [41].

\section{Effects of lactobacilli on cytokine production by human peripheral blood mononuclear cells (PBMCs)}

PBMCs were isolated from the donors' peripheral blood by Ficoll gradient centrifugation. PBMCs $\left(2 \times 10^{6}\right.$ cell $\left./ \mathrm{mL}\right)$ were incubated at $37^{\circ} \mathrm{C}\left(5 \% \mathrm{CO}_{2}\right)$ for $2 \mathrm{~h}$ and then incubated alone (the control) or with either $S$. mutans ATCC $25175\left(10^{7} \mathrm{CFU} / \mathrm{mL}\right)$ or oral lactobacilli $\left(10^{7} \mathrm{CFU} / \mathrm{mL}\right)$ for $12 \mathrm{~h}$ at $37^{\circ} \mathrm{C}\left(5 \% \mathrm{CO}_{2}\right)$. The suspensions in the wells were aspirated and washed with RPMI 1640 medium (Thermo Fisher, Shanghai, China). For the double-challenge, $S$. mutans ATCC 25175 -stimulated PBMCs $\left(2 \times 10^{6}\right.$ cell $\left./ \mathrm{mL}\right)$ were incubated either alone or with oral lactobacilli $\left(10^{8}\right.$ $\mathrm{CFU} / \mathrm{mL}$ ) for $24 \mathrm{~h}$ prior to cytokine analysis [11]. The production of anti-inflammatory IL-10 cytokine and pro-inflammatory IL-12p70 cytokine were determined by enzyme linked immunosorbent assay (ELISA; R\&D Systems, Minneapolis, MN, USA).

\section{Statistical analysis}

All experiments were performed in triplicate. Results were analyzed using Student's $t$-test by SPSS 19.0. Statistical significance was set at $P<0.05$.

\section{Abbreviations}

CFU: Colony forming unit; DNA: Deoxyribonucleic acid; ELISA: Enzyme linked immunosorbent assay; EPS: Extracellular polysaccharides; IL: Human peripheral blood mononuclear cells cytokine interleukin; MRS: De man, Rogosa, Sharpe; PBS: Phosphate buffered saline; PYG: Peptone yeast glucose; TSB: Tryptone soy broth

\section{Acknowledgements}

We are grateful to Dr. Jian Zhang from Wuxi No. 2 People's Hospital for his assistance with the oral samples, and Prof. Jian Jin (Jiangnan University) for providing the oral epithelial carcinoma cell line (KB).

\section{Funding}

This research was supported by the National Natural Science Foundation of China (31771955) and the Program for Changjiang Scholars and Innovative Research Team (No. IRT_15R26). The funding sources had no role in the design of the study and collection, analysis, and interpretation of data, or preparation of the manuscript.

\section{Availability of data and materials}

The data that support the findings of this study are available from the corresponding author upon reasonable request.

\section{Authors' contributions}

FF, GD designed the experiments and wrote the manuscript; FF, GD have contributed to the acquisition, analysis and interpretation of the data; JX, QL, XX performed the experiments and participated to the interpretation of data. All authors read and approved the final manuscript.

\section{Ethics approval and consent to participate}

This study was approved by the ethics committee of Jiangnan University. The written informed consent was obtained from all participants.

Consent for publication

Not applicable.

Competing interests

The authors declare that they have no competing interests.

\section{Publisher's Note}

Springer Nature remains neutral with regard to jurisdictional claims in published maps and institutional affiliations.

\section{Author details \\ ${ }^{1}$ Key Laboratory of Industrial Biotechnology, Ministry of Education, School of Biotechnology, Jiangnan University, Wuxi 214122, China. ${ }^{2}$ State Key Laboratory of Food Science and Technology, Jiangnan University, Wuxi 214122, China. ${ }^{3}$ The Key Laboratory of Carbohydrate Chemistry and Biotechnology, Ministry of Education, Jiangnan University, Wuxi 214122, China.}

Received: 3 January 2018 Accepted: 10 December 2018

Published online: 22 December 2018

\section{References}

1. Çaglar E, Kargul B, Tanboga I. Bacteriotherapy and probiotics' role on oral health. Oral Dis. 2005;11(3):131-7.

2. Oo KM, Lwin AA, Kyaw YY, Tun WM, Fukada K, Goshima A, et al. Safety and long-term effect of the probiotic FK-23 in patients with hepatitis $C$ virus infection. Biosci Microbiota Food Health. 2016;35(3):123-8.

3. Michalickova D, Minic R, Dikic N, Andjelkovic M, Kostic-Vucicevic M, Stojmenovic T, et al. Lactobacillus helveticus Lafti L10 supplementation reduces respiratory infection duration in a cohort of elite athletes: a randomized, double-blind, placebo-controlled trial. Appl Physiol Nutr Metab. 2016;41(7):782-9.

4. Karlsson M, Scherbak N, Khalaf H, Olsson PE, Jass J. Substances released from probiotic Lactobacillus rhamnosus GR-1 potentiate NF-kappaB activity in Escherichia coli-stimulated urinary bladder cells. FEMS Immumol Med Microbiol. 2012;66(2):147-56.

5. Nase L, Hatakka K, Savilahti E, Saxelin M, Ponka A, Poussa T, et al. Effect of long-term consumption of a probiotic bacterium, Lactobacillus rhamnosus GG, in milk on dental caries and caries risk in children. Caries Res. 2001;35(6): 412-20.

6. Krasse P, Carlsson B, Dahl C, Paulsson A, Nilsson A, Sinkiewicz G. Decreased gum bleeding and reduced gingivitis by the probiotic Lactobacillus reuteri. Swed Dent J. 2006;30(2):55-60.

7. Selwitz RH, Ismail Al, Pitts NB. Dental caries. Lancet. 2007:369(9555):51-9.

8. Kolenbrander PE. Oral microbial communities: biofilms, interactions, and genetic systems. Annu Rev Microbiol. 2000;54:413-37.

9. Walter J, Schwab C, Loach DM, Ganzle MG, Tannock GW. Glucosyltransferase a (GtfA) and inulosucrase (Inu) of Lactobacillus reuteri TMW1.106 contribute to cell aggregation, in vitro biofilm formation, and colonization of the mouse gastrointestinal tract. Microbiology. 2008;154(1):72-80.

10. Boris S, Suarez JE, Vazquez F, Barbes C. Adherence of human vaginal lactobacilli to vaginal epithelial cells and interaction with uropathogens. Infect Immun. 1998;66(5):1985-9.

11. Foligne B, Nutten S, Grangette C, Dennin V, Goudercourt D, Poiret S, et al. Correlation between in vitro and in vivo immunomodulatory properties of lactic acid bacteria. World J Gastroentero. 2007;13(2):236-43.

12. Jenzano JW, Hogan SL, Lundblad RL. Factors influencing measurement of human salivary lysozyme in lysoplate and turbidimetric assays. J Clin Microbiol. 1986:24(6):963-7.

13. Teughels W, Durukan A, Ozcelik O, Pauwels M, Quirynen M, Haytac MC. Clinical and microbiological effects of Lactobacillus reuteri probiotics in the treatment of chronic periodontitis: a randomized placebo-controlled study. J Clin Periodontol. 2013;40(11):1025-35.

14. Morales A, Carvajal P, Silva N, Hernandez M, Godoy C, Rodriguez G, et al. Clinical effects of Lactobacillus rhamnosus in non-surgical treatment of chronic periodontitis: a randomized placebo-controlled trial with 1-year follow-up. J Periodontol. 2016;87(8):944-52. 
15. Riccia DN, Bizzini F, Perilli MG, Polimeni A, Trinchieri V, Amicosante G, et al Anti-inflammatory effects of Lactobacillus brevis (CD2) on periodontal disease. Oral Dis. 2007;13(4):376-85.

16. Vicario M, Santos A, Violant D, Nart J, Giner L. Clinical changes in periodontal subjects with the probiotic Lactobacillus reuteri Prodentis: a preliminary randomized clinical trial. Acta Odontol Scand. 2013;71(3-4):813-9.

17. Terai T, Okumura T, Imai S, Nakao M, Yamaji K, Ito M, et al. Screening of probiotic candidates in human oral bacteria for the prevention of dental disease. PLoS One. 2015;10(6):e0128657.

18. Jiang Q, Stamatova I, Kainulainen V, Korpela R, Meurman JH. Interactions between Lactobacillus rhamnosus GG and oral micro-organisms in an in vitro biofilm model. BMC Microbiol. 2016;16(1):1-11.

19. Mishra R, Tandon S, Rathore M, Banerjee M. Antimicrobial efficacy of probiotic and herbal oral rinses against Candida albicans in children: a randomized clinical trial. Int J Clin Pediatr Dent. 2016;9(1):25-30.

20. Takahashi N, Schachtele CF. Effect of pH on the growth and proteolytic activity of Porphyromonas gingivalis and Bacteroides intermedius. J Dent Res. 1990;69:1266-9.

21. Juárez Tomás MS, Ocaña VS, Wiese B, Nader-Macías ME. Growth and lactic acid production by vaginal Lactobacillus acidophilus CRL 1259, and inhibition of uropathogenic Escherichia coli. J Med Microbiol. 2003;52:1117-24.

22. Shokri D, Khorasgani MR, Mohkam M, Fatemi SM, Ghasemi Y, Taheri-Kafrani A. The inhibition effect of lactobacilli against growth and biofilm formation of Pseudomonas aeruginosa. Probiotics Antimicro. 2018;10(1):34-42.

23. Maragkoudakis PA, Zoumpopoulou G, Miaris C, Kalantzopoulos G, Pot BD, Tsakalidou E. Probiotic potential of Lactobacillus strains isolated from dairy products. Int Dairy J. 2006;16(3):189-99.

24. Hertzberger R, Arents J, Dekker HL, Pridmore RD, Gysler C, Kleerebezem M, et al. $\mathrm{H}_{2} \mathrm{O}_{2}$ production in species of the Lactobacillus acidophilus group: a central role for a novel NADH-dependent flavin reductase. Appl Environ Microbiol. 2014;80(7):2229-39.

25. Candela M, Seibold G, Vitali B, Lachenmaier S, Eikmanns BJ, Brigidi P. Real-time PCR quantification of bacterial adhesion to Caco-2 cells: competition between bifidobacteria and enteropathogens. Res Microbiol. 2005;156(8):887-95.

26. Saeed A, Heczko PB. Surface properties of lactobacilli isolated from healthy subject. Folia Med Cracov. 2007;48(1-4):99-111.

27. Georgieva R, Yocheva L, Tserovska L, Zhelezova G, Stefanova N, Atanasova A, et al. Antimicrobial activity and antibiotic susceptibility of Lactobacillus and Bifidobacterium spp. intended for use as starter and probiotic cultures. Biotechnol Biotechnol Equip. 2015;29(1):84-91.

28. Kõll P, Mandar R, Marcotte H, Leibur E, Mikelsaar M, Hammarstro L. Characterization of oral lactobacilli as potential probiotics for oral health. Oral Microbiol Immun. 2008;23(2):139-47.

29. Yadav R, Puniya AK, Shukla P. Probiotic properties of Lactobacillus plantarum RYPR1 from an indigenous fermented beverage Raabadi. Front Microbiol. 2016;7:1683.

30. Krajden S, Fuksa M, Anderson J, Kempston J, Boccia A, Petrea C, et al. Examination of human stomach biopsies, saliva, and dental plaque for Campylobacter pylori. J Clin Microbiol. 1989;27(6):1397-8.

31. Fang F, Feng T, Du G, Chen J. Evaluation of the impact on food safety of a Lactobacillus coryniformis strain from pickled vegetables with degradation activity against nitrite and other undesirable compounds. Food Addit Contam Part A Chem Anal Control Expo Risk Assess. 2016;33(4):623-30.

32. Gezginc Y, Topcal F, Comertpay S, Akyol I. Quantitative analysis of the lactic acid and acetaldehyde produced by Streptococcus thermophilus and Lactobacillus bulgaricus strains isolated from traditional Turkish yogurts using HPLC. J Dairy Sci. 2015;98(3):1426-34.

33. Yang Z, Li S, Zhang X, Zeng X, Li D, Zhao Y, Zhang J. Capsular and slimepolysaccharide production by Lactobacillus rhamnosus JAAS8 isolated from Chinese sauerkraut: potential application in fermented milk products. J Biosci Bioeng. 2010;110(1):53-7

34. Dubois M, Gilles JK, Hamilton JK, Rebers PA, Smith F. Colorimetric methods for determination of sugars and related substances. Anal Chem. 1956;28: 350-6.

35. Kullisaar T, Zilmer M, Mikelsaar M, Vihalemm T, Annuk H, Kairane C, Kilk A. Two antioxidative lactobacilli strains as promising probiotics. Int J Food Microbiol. 2002;72(3):215-24.

36. Andrews JM. Determination of minimum inhibitory concentrations. J Antimicrob Chemother. 2001;48(Suppl 1):5-16.

37. EFSA. Update of the criteria used in the assessment of bacterial resistance to antibiotics of human or veterianry importance. EFSA J. 2008;732:1-15.
38. Collado M, Meriluoto J, Salminen S. Adhesion and aggregation properties of probiotic and pathogen strains. Eur Food Res Technol. 2008;226(5):1065-73.

39. Reid G, McGroarty JA, Angotti R, Cook RL. Lactobacillus inhibitor production against Escherichia coli and coaggregation ability with uropathogens. Can J Microbiol. 1988;34(3):344-51.

40. Ambalam P, Kondepudi KK, Nilsson I, Wadstrom T, Ljungh A. Bile stimulates cell surface hydrophobicity, Congo red binding and biofilm formation of Lactobacillus strains. FEMS Microbiol Lett. 2012;333(1):10-9.

41. Hudault S, Lievin V, Bernet-Camard MF, Servin AL. Antagonistic activity exerted in vitro and in vivo by Lactobacillus casei (strain GG) against Salmonella typhimurium C5 infection. Appl Environ Microbiol. 1997;63(2): 513-8.

42. Jacobsen CN, Rosenfeldt Nielsen V, Hayford AE, Moller PL, Michaelsen KF, Paerregaard A, et al. Screening of probiotic activities of forty-seven strains of Lactobacillus spp. by in vitro techniques and evaluation of the colonization ability of five selected strains in humans. Appl Environ Microbiol. 1999; 65(11):4949-56.

\section{Ready to submit your research? Choose BMC and benefit from:}

- fast, convenient online submission

- thorough peer review by experienced researchers in your field

- rapid publication on acceptance

- support for research data, including large and complex data types

- gold Open Access which fosters wider collaboration and increased citations

- maximum visibility for your research: over $100 \mathrm{M}$ website views per year

At BMC, research is always in progress.

Learn more biomedcentral.com/submissions 